\title{
ANALYSIS \\ What healthcare financing changes are needed to reach universal coverage in South Africa?
}

\author{
Diane McIntyre
}

The national health insurance proposed for South Africa aims to achieve a universal health system. The best way to identify the financing mechanism that is best suited to achieving this goal is to consider international evidence on funding in universal health systems. The evidence from Organisation for Economic Cooperation and Development countries and a number of middleincome countries that have achieved universal coverage clearly indicates that mandatory pre-payment financing mechanisms (i.e. general tax funding, in some cases supplemented by mandatory health insurance) must dominate, with a clearly specified, complementary role for voluntary or private health insurance.

S Afr Med J 2012;102(6):489-490.
The global health policy agenda is dominated by discussions about the need for health systems to achieve universal coverage. There are two key elements to the concept of universal coverage: providing financial protection from the costs of healthcare and ensuring access to needed health services for all. ${ }^{1-3}$ This implies that the healthcare financing mechanism must enable income cross-subsidies (from the rich to the poor) and risk crosssubsidies (from the healthy to the ill). ${ }^{3}$

It is clear from the recent Green Paper on National Health Insurance (NHI) ${ }^{4}$ that the core objective of the proposed health system changes is to move towards universal coverage. A key question is what kind of healthcare financing system should South Africa pursue if we are to achieve universal coverage?

It is helpful to look at other countries that are regarded as having universal health systems. Most of these are high-income Organisation for Economic Cooperation and Development (OECD) countries, although a few middle-income countries (such as Colombia, Costa Rica, Cuba and Thailand) are also frequently held up as examples of universal systems. ${ }^{3}$

Fig. 1 provides an overview of countries that have belonged to the OECD for the longest period (excluding some of the smallest countries such as Iceland). All, with the exception of the USA, are regarded as having universal health systems. There is a striking pattern across these OECD countries and the middle-income countries that also have universal systems. First, mandatory prepayment financing mechanisms (i.e. general tax funding, in some cases supplemented by social or national health insurance) is the dominant funding mechanism, accounting for $70 \%$ or more of total healthcare expenditure in almost all cases. Second, private voluntary insurance is very limited, as are out-of-pocket payments in general. Private voluntary insurance exists in all countries, but has a clearly defined role that supports the predominantly publicly financed health system. Those with the largest private insurance

Diane McIntyre is Professor in the Health Economics Unit, Department of Public Health and Family Medicine, University of Cape Town. levels (over $10 \%$ of total healthcare expenditure) are Canada and France. In Canada, about two-thirds of the population have complementary private health insurance, mostly through employment-based group plans, to cover the services not covered through public funds (e.g. vision and dental care, and outpatient prescription drugs). ${ }^{5}$ In France, almost $90 \%$ of the population has complementary private insurance through employment-based mutual associations, to cover the cost-sharing (co-payments) required by the social health insurance system. ${ }^{5}$ Korea stands out as a country with high levels of out-of-pocket payments, as a result of the high levels of co-payments in its social health insurance system. This means limited access to healthcare for poorer groups ${ }^{6}$ and raises questions about whether Korea really has universal financial protection.

South Africa has a financing pattern that more resembles that of the USA, which is not a health system that any sensible South African would wish to emulate, than countries with universal coverage. It is noteworthy that South Africa has the highest percentage share of private voluntary insurance in the world. ${ }^{7}$ Yet, only $16 \%$ of the population benefits from these resources. In my opinion, the international evidence is clear; if South Africa is to achieve a universal health system, we need to increase the relative share of mandatory prepayment funding (from general tax and possibly additional mandatory contributions, whether in the form of dedicated health taxes or mandatory insurance payments), and private health insurance should have a clearly defined complementary role that is defined in relation to the dominant publicly funded services.

It is no accident that the 2010 World Health Report, ${ }^{3}$ devoted to the issue of universal coverage, reached the conclusion that mandatory prepayment (or public funding) has to be the core of any universal health system; this report was based on an extensive review of the international evidence. Mandatory prepayment funds in universal systems are 'public' in the sense that they are used for the benefit of all; they can be used to purchase needed healthcare for the whole population from public and private providers. The funds are also 'public' in the sense that they are pooled in such a way as to ensure that there are income and risk cross-subsidies. As indicated earlier, these cross-subsidies are central to universal coverage.

The issue of cross-subsidies is crucial, as some 'smart Alec' is bound to say, 'The answer is simple, just make medical schemes mandatory and then we would have over $80 \%$ of funding in the 


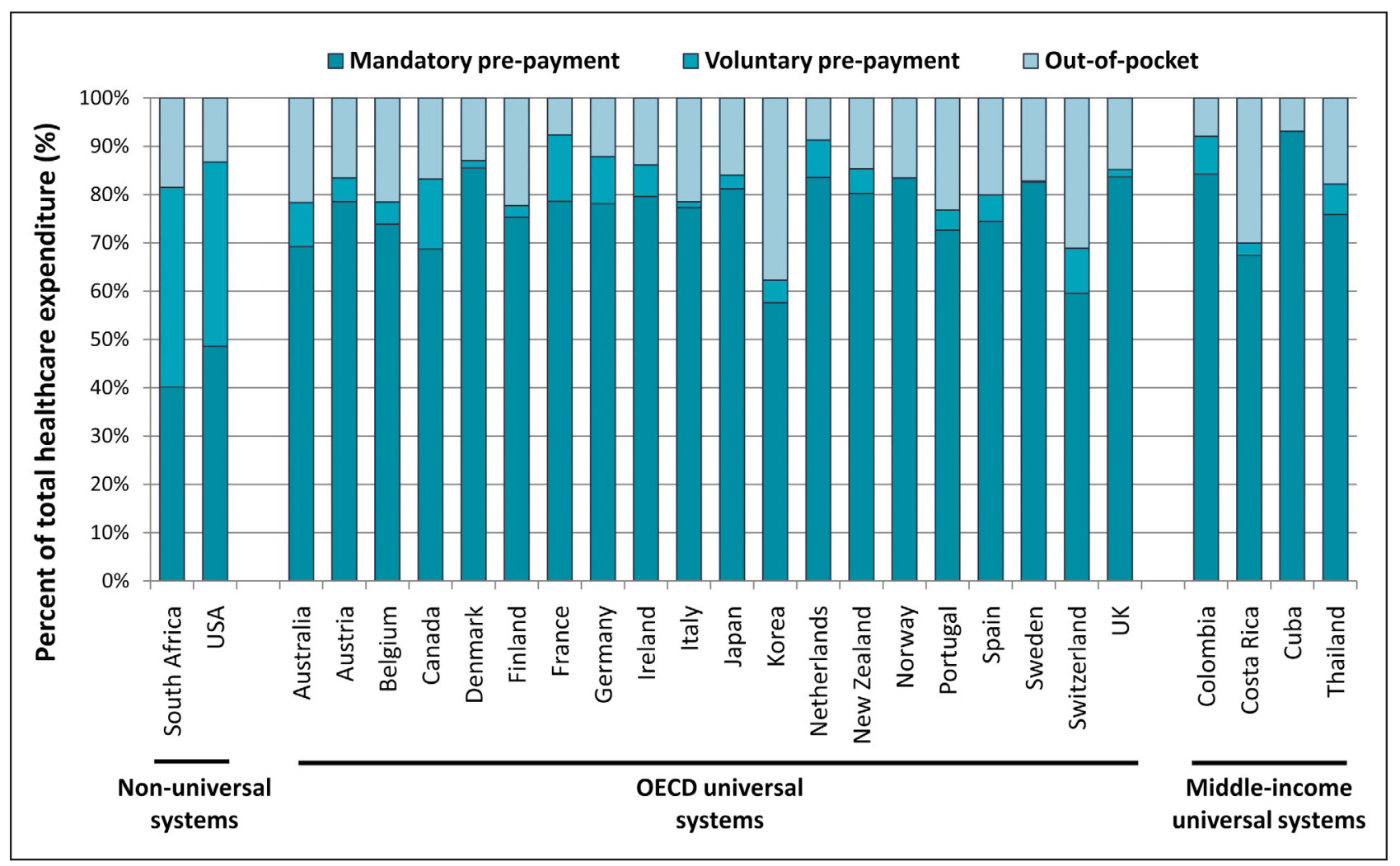

Fig. 1. Financing mechanisms in countries with universal health systems compared with SA and the USA (2009). Source: World Health Organization, National Health Accounts dataset (http://www.who.int/nha/en).

form of mandatory prepayment'. However, what would occur is that funds would be kept separate and only benefit those who are contributing to schemes (currently $16 \%$ of the population or about $40 \%$ if all formal-sector workers and their dependents were legally required to belong to these schemes); there would not be substantive income and risk cross-subsidies between the medical schemes' pool and the general tax funding pool. There seems to be consensus among stakeholders in South Africa that it is not affordable to create an integrated funding pool by means of covering the entire population through medical schemes.

Moving towards a predominantly publicly funded health system with a specified role for private voluntary health insurance will take time. What is required in the short term is for Treasury to be responsive to submissions to gradually increase the allocations to the health sector from general tax revenue, to enable the Department of Health to implement its plans to strengthen substantially both primary healthcare and hospital services, as outlined in the NHI Green Paper and other recent policy documents. It is likely that it will be necessary to supplement this with additional taxes dedicated to the health sector, such as an income tax surcharge, payroll tax on employers and/or 'sin taxes' on tobacco and alcohol, which can be phased in after initial improvements to the public health system have been achieved.
When universal entitlements to specified services are formalised in legislation, it will be important to specify the complementary role of private voluntary insurance. Through this overall process, the relative distribution of healthcare funding across different financing mechanisms will shift gradually to the pattern that we see in countries that have already achieved universal coverage.

\footnotetext{
1. Carrin G, James C. Reaching Universal Coverage via Social Health Insurance: Key Design Features in the Transition Period. Discussion Paper Number 2 - 2004. Geneva: WHO, 2004.

2. Kutzin J. Current reforms aiming at the extension of social protection in health: linking up mixed health financing sub-systems. In: ILO, GTZ \& WHO, eds. Extending Social Protection in Health: Developing countries' experiences, lessons learnt and recommendations. Eschborn: Deutsche Gesellschaft für Technische Zusammenarbeit (GTZ), 2007.

3. World Health Organization. Health Systems Financing: The Path to Universal Coverage. World Health Report 2010. Geneva: WHO, 2010.

4. Department of Health. National Health Act (Act 61 of 2003): Policy on National Health Insurance. Government Gazette 34523. Pretoria: Department of Health, 2011.

5. Thomson S, Osborn R, Squires D, Reed S, eds. International Profiles of Health Care Systems, 2011. New York: The Commonwealth Fund, 2011.

6. Yang B. Health insurance in Korea: opportunities and challenges. Health Policy Planning 6. Yang B. Health

7. Drechsler D, Jutting J. Is there a role for private health insurance in developing countries? Berlin:
. German Institute for Economic Research, 2005.
}

Accepted 18 January 2012. 